\title{
High Dose 3D Conformal Radiotherapy of Prostate Cancer Using Spaceoar Gel
}

\author{
Sema Yilmaz Rakici (Corresponding author) \\ Departments of Radiation Oncology, \\ Recep Tayyip Erdogan University Medical School, Rize, Turkey \\ E-mail: sema.rakici@erdogan.edu.tr \\ Fatih Mehmet Inecikli \\ Departments of Radiology, \\ RecepTayyip Erdogan University Medical School, Rize, Turkey \\ E-mail: drinecikli@gmail.com \\ Nilgun Ozbek Okumus \\ Department of Radiation Oncology, \\ Ondokuz Mayis University Medical School, Samsun, Turkey \\ E-mail: nozbekokumus@yahoo.com \\ Hakki Uzun \\ Departments of Urology \\ RecepTayyip Erdogan University Medical School, Rize, Turkey \\ E-mail: hakuzun@hotmail.com \\ Gulnihal Tufan \\ Departments of Medical Oncology, \\ RecepTayyip Erdogan University Medical School, Rize, Turkey \\ E-mail: gntufan@hotmail.com \\ Ahmet Sen \\ Departments of Anesthesiology, \\ RecepTayyip Erdogan University Medical School, Rize, Turkey \\ E-mail: ahmetsenau@gmail.com \\ Emine Canyilmaz \\ Department of Radiation Oncology, \\ Karadeniz Technical University Medical School, Trabzon, Turkey \\ E-mail: dremocan@yahoo.com \\ Hasan Morcali \\ Departments of Radiation Oncology, \\ Recep Tayyip Erdogan University Medical School, Rize, Turkey \\ E-mail: morcali_dr@yahoo.com.tr \\ Zihni Acar Yazici \\ Department of Microbiology, \\ RecepTayyip Erdogan University Medical School, Rize, Turkey \\ E-mail: zihni.yazici@erdogan.edu.tr
}

\begin{abstract}
The aim of this study was to investigate the applicability of high dose radiation therapy following the administration of SpaceOar Hydrogel to decrease rectal toxicity in patients with prostate cancer who had received definitive three-dimensional conformal radiation therapy. Seven patients with a diagnosis of prostate cancer received, under general anesthesia, $10 \mathrm{ml}$ of prostate SpaceOar hydrogel injections transperineally into the space between the prostate and the rectal front wall under the guidance of
\end{abstract}


transrectal ultrasonography. Abdominal tomography and magnetic resonance images of the patients were taken before and after the application of hydrogel. Using both imaging sets and similar algorithms, 3D conformal radiotherapy plans were made that aided in making the calculations. The radiation dose to be applied was calculated from the dose-volume histograms of the target and at risk organs of the patients with tailor-made plans. In the treatment of prostate cancer patients with and without hydrogel plans, there was a statistically significant difference between the rectal V70 and V50 doses, which were $20 \% \pm 14.9$ vs $11 \% \pm 2.2$ ( p:0.002), and $34 \pm 7.9$ vs $28.2 \pm 11$ (p: 0.048), respectively. The D95 and D5 values were similar in all patients with and without hydrogel plans. Rectal toxicity decreased in patients with a distance of $>15 \mathrm{~mm}$ ( $\mathrm{p}=0.053$ ). Consequently 3D conformal radiotherapy can be successfully and safely applied at high dose with low toxicity to prostate cancer patients after placing hydrogel between the rectum and prostate.

Keywords: Prostate cancer, radiotherapy, spaceoar hydrogel, rectal toxicity

DOI: $10.7176 / J S T R / 5-6-08$

\section{Introduction}

The incidence of prostate cancer (PC) ranks first in the developed world according to 2010 data. It is an important life-long health concern for males. Surgery is one of the treatment options for early stage PC(Jemal et al., 2011). However, serious complications are the norm for surgical therapies. Among these are incontinence $(67 \%)$, rectal injury $(15 \%)$, and narrowing of the bladder neck $(29 \%)$ (Garzotto \& Wajsman, 1998; Stephenson et al., 2004). For this reason, radiotherapy (RT) is considered to constitute a good alternative to surgery (Bucci, Bevan, \& Roach, 2005). In addition, occurrence of impotence and incontinence is less frequent in RT than surgery(Robinson, Moritz, \& Fung, 2002). It has been established that dose escalation in RT improves the biochemical parameters (Viani, Stefano, \& Afonso, 2009). However, the dose escalation is limited because of rectal toxicity (Brenner, 2004). Methods for decreasing rectal toxicity have been developed. These include advanced RT techniques like intensity modulated radiotherapy (IMRT) and image guided radiotherapy (IGRT). There are other applications that have been developed to protect the rectum by increasing the distance between the prostate and rectum in order to decrease the effect of radiation (Nguyen et al., 2013; Pinkawa et al., 2011; Pinkawa et al., 2013; Pinkawa, Schubert, Escobar-Corral, Holy, \& Eble, 2015; Prada et al., 2007; Prada et al., 2009; Susil, McNutt, DeWeese, \& Song, 2010; Uhl et al., 2013). One such application is the injection of Prostate Spacer Hydrogel (SpaceOAR ${ }^{\text {TM }}$ System, Augmenix Inc., Waltham, MA) between rectum and prostate. In this study, we investigated the protection that hydrogel proveided against rectal toxicicty induced by high dose $3 \mathrm{D}$ conformal radiotherapy (3D-CRT) in prostate cancer patients.

\section{Methods and Materials \\ Patients}

In this study, to reduce the rectal toxicity of high dose RT, hydrogel was injected between the prostate and rectum. Using abdominal tomography (CT) imaging before and after the injection of hydrogel, 3DCRT plans of patients were made and compared dosimetrically. In addition, rectal radiotoxicity levels were evaluated in patients receiving hydrogel in accordance with the plans. This method was applied to 7 patients admitted to the Oncology Department between April 2014 and April 2015. The patients had pathologically confirmed prostate cancer with T1 and T2, N0 and M0. This type of therapy used to be a routine procedure sanctioned by the Ministry of Health. However, after the initiation of the study, the provision of hydrogel for this type of treatment has been discontinued by the state because of cost concerns. Therefore, we were unable to recruit more patients. However, the results proved to be beneficial for the patients, encouraging submission for publication.

\section{Placement of Hydrogel}

Prostate spacer hydrogel is polyethylene glycol that polymerises in 10 seconds. The gel is injected by using an $18 \mathrm{G}$ needle into the perineal region between the prostate and rectum under the guidance of transrectal ultrasonography. To establish sufficient space between the retroprostatic fascia and the rectal front plane for the hydrogel, $25 \mathrm{ml}$ of isotonic solution is injected prior to the injection of the gel. The injected hydrogel solidifies within 10 seconds in the perirectal adipose tissue and thereby separates the prostate and rectum. Thus, the space increases by about $14-15 \mathrm{~mm}$ after the injection of the hydrogel. This can be confirmed by magnetic resonance imaging (MRI). The injection process takes about 5 minutes. The 7 patients who received the hydrogel were transferred to operation theatres to provide a sterile environment. The procedure was performed under general anesthesia to avoid pain sensation, to

56 | P a g e

www.iiste.org 
provide psychologic comfort and to allow easy application. The patients were followed for two hours in the postoperative care room before discharging to the ward. It is important that the space created by the injection of the hydrogel is retained for three months for the duration of RT. The hydrogel is resorbed within 6 months of its application and discharged by the kidneys (Pinkawa et al., 2015). Axial T2 weighted pelvic MRI images of a patient immediately after the injection of the hydrogel and 9 months after the application are shown in figure 1, which show that the hydrogel has disappeared completely within this period.

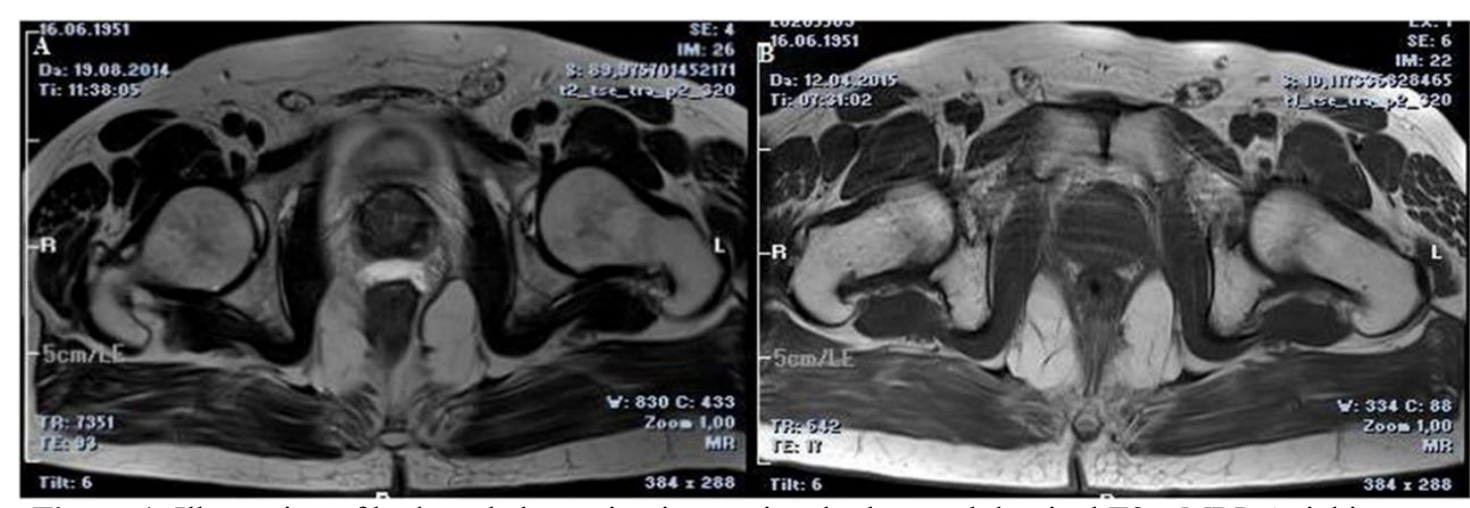

Figure 1. Illustration of hydrogel absorption in a patient by lower abdominal T2w MRI. Axial images (A) post hydrogel/pre 3D CRT, and (B) 9 months post hydrogel from the same patient.

\section{Treatment Planning and Therapy}

Abdominal CT scanning of patients for planning were performed on full bladder achieved by water consumption at a rate of $0.5 \mathrm{~L} / 30 \mathrm{~min}$. Patients presented with enlarged recti on scanning were asked to discharge intestinal contents by natural means. Scans were set at $3 \mathrm{~mm}$ sections and taken in supine position before (CT1) and after (CT2) application of hydrogel using LB Toshiba simulator CT. Furthermore, T2 weighted MRI images were taken to allow post-injection image fusion. The volumes were contoured by the same radiation oncologist in order to avoid operator dependent variations. The prostate, seminal vesicles, rectum, bladder and the other normal tissues were identified and drawn. The rectum contoured from the anal canal to the rectosigmoid junction (Pinkawa et al., 2006). Gross tumor volume was identified by the prostate tissue as imaged by CT. The clinical target volume was assessed on the basis of the state of the patient. PTV were set to include prostate only in low risk patients (T1, 2a and Gleason score $\leq 6$ or PSA $<10 \mathrm{ng} / \mathrm{mL}$ ), the prostate and proximal seminal vesicles in medium risk patients (T2b, T2c or Gleason score of 7 or PSA 10-20 ng/mL), and the prostate, seminal vesicles and periprostatic lymph nodes in high risk patients (T3, T4 or Gleason Score of 8-10 or PSA $>20 \mathrm{ng} / \mathrm{mL}$ ). In planning RT, a margin of $5 \mathrm{~mm}$ in the posterior is recommended for PTV (Nederveen et al., 2002; Teh et al., 2003), which was the case in this study, too. Simultaneous cone beam CT (CBCT) scan imaging was used to confirm compliance with the plans during treatment.

Treatment plans were drawn using 3D-CRT with and without hydrogel plans under the area technique ${ }^{11}$ with portal angles of 30, 90, 150, 270, and 330 degrees (CMS XIO, release 5.00.01 treatment planning system, with $18 \mathrm{MV}$ photon). CT images from both plans and isodose distributions of patients are shown in Figure 2. It is apparent that the rectum is protected in the hydrogel plan. The ICRU reference point was defined within PTV and the planning was escalated in 39 fractions from 2 Gy to 78 Gy per day. More than $99 \%$ of the PTV was to receive at least $95 \%$ of the dose and the maximum dose was adjusted to be less than $107 \%$ of the defined value. Based on the recommendations of RTOG (Nederveen et al., 2002; Teh et al., 2003), plans of V50 $<50 \%$ and V70 $<20 \%$ for the rectum were made and dose volume histograms (DVH) were drawn. Both plans were dosimetrically compared. For the sample patient, DVH of both rectal plans are shown in Figure 3. The rectal dose was significantly less with the hydrogel plan than with the one without. 

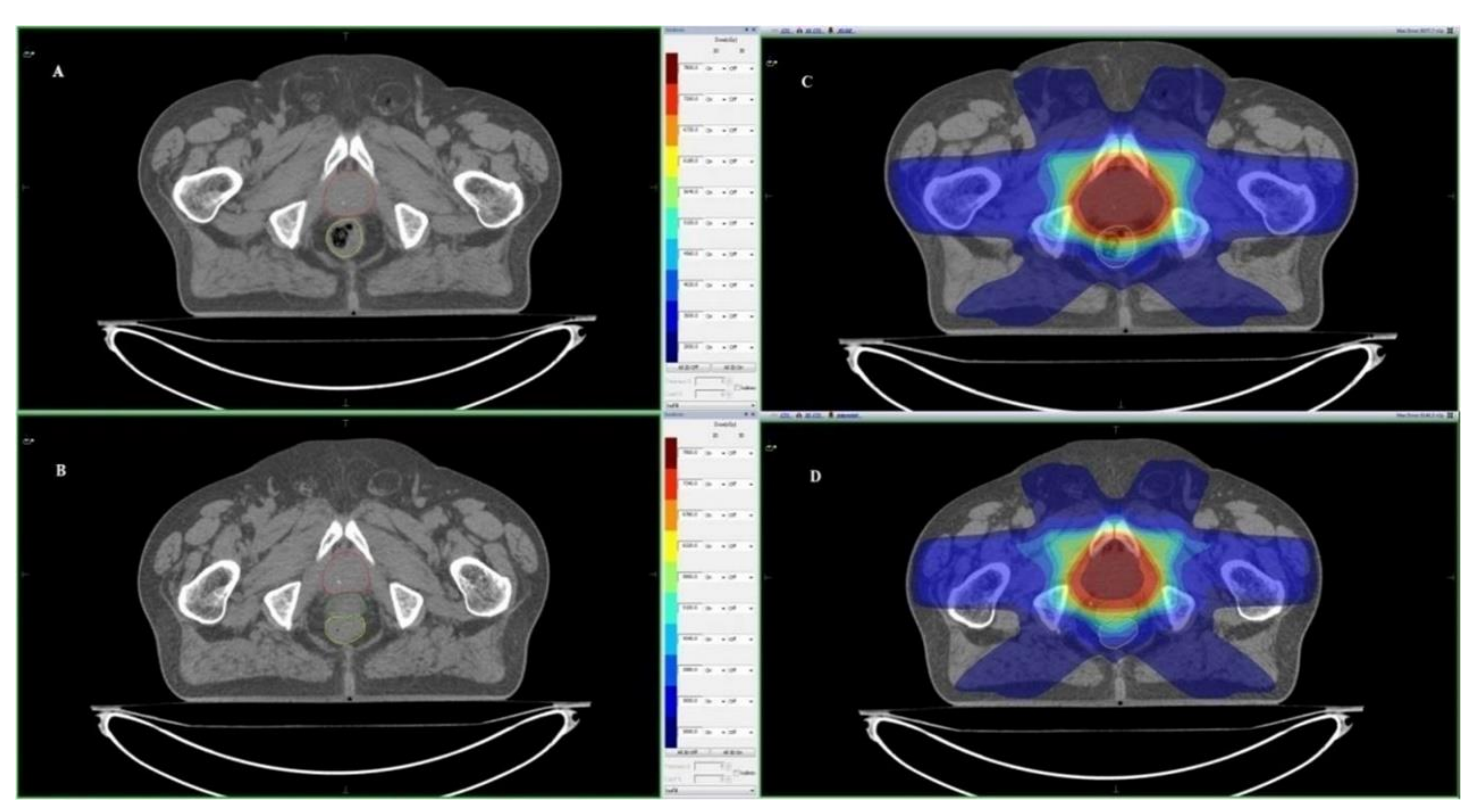

Figure 2. Axial plane abdominal CT images before (A) and after (B) hydrogel, and images of hydrogel planned by the conformal techniques before (C) and after (D) isodose distributions.
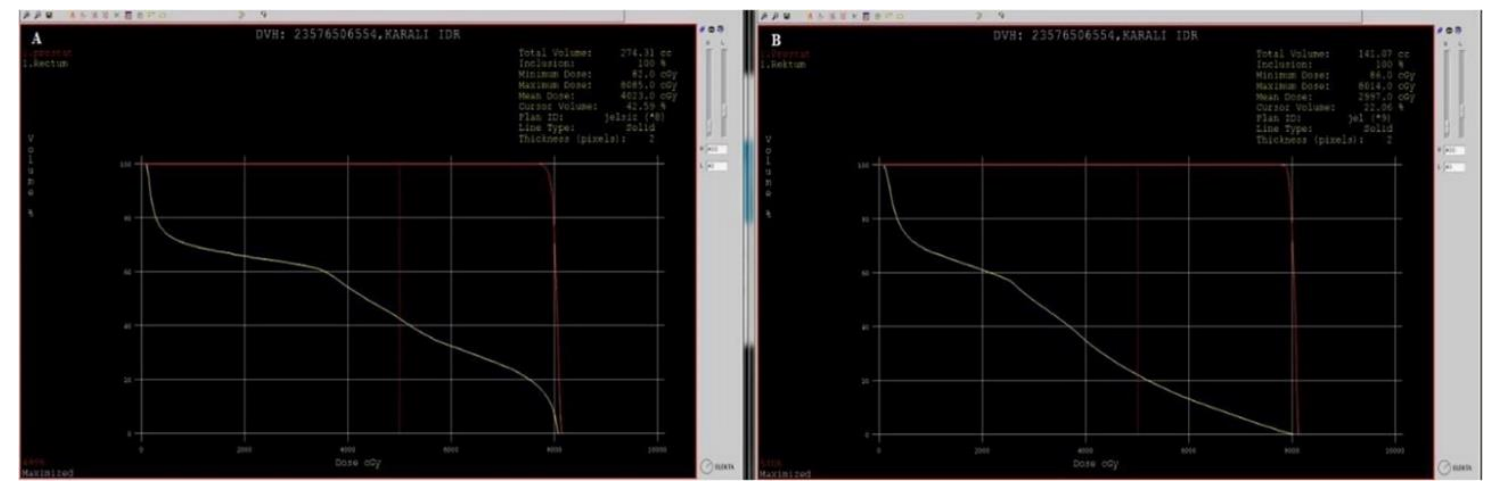

Figure 3. Rectal DVHs with and without hydrogel.

\section{Statistical Analysis}

DVH were used in the comparison of the target volume and at-risk organ doses in all of the treatment plans. The Mann-Whitney U-test for non-parametric-interval data and the chi $^{2}$-test for ordinal/nominal data were used to compare the groups. All statistical tests were two-sided, with a threshold for statistical significance of $\mathrm{p}<0.05$. Statistical analysis was carried out utilizing SPSS version 13.

\section{RESULTS}

Patient and tumor characteristics are given in Table 1. In the treatment of patients with hydrogel plans, there was a statistically significant difference between the rectal V70 and V50 doses. There was no significant difference between the two plans for other parameters. The dosimetric results are summarized in Table 2.

Posterior displacements have been analyzed at three different representative levels in the mid-sagittal plane: the superior prostate/ seminal vesicle (point P1), the level of the bladder neck (point P2), and the inferior prostate (point P3). The definitions of the base, middle and apex, as well as points P1, P2 and P3, are demonstrated in Figure 4. The P1-3 measurements of the patients are shown in table 1. While the highest values correspond to $\mathrm{P} 1$, the lowest match with $\mathrm{P} 3$. The average distance between the prostate and rectum of the patients was 14.2 (range 10.5-25.2) $\mathrm{mm}$ from the centre of the rectum. This distance has no significant correlation with rectal toxicity and tenesmus $(p=0.07)$. However, there was a drop in rectal toxicity in patients with a distance of $>15 \mathrm{~mm}$ between the rectum and prostate $(\mathrm{p}=0.053)$.

There was no complication pertaining to the hydrogel application except for one patient had more than ten tenesmuses a day, which resisted symptomatic treatment. Patient's compalints gradually subsided as 
therapy progressed. Symptoms of radiation proctitis were assessed via the Radiation Therapy Oncology Group/ European Organization for Research and Treatment of Cancer (RTOG/EORTC) gastrointestinal (GI ) and genitourinary (GU) toxicity score (acute and late) (Cox, Stetz, \& Pajak, 1995). Weekly and at the completion of RT, patients were evaluated for acute GU and GI toxicity. During follow-up toxicity assessments were performed 3, 6, 9, 12 and 30 months after the end of radiation therapy (RTOG/ EORTC). The patients had no GU syptoms including polyuria, nocturia, or hematuria. One patient experienced grade 2 acute GI toxicity, requiring analgesics and medication, including rectal discomfort and tenesmus. No patient experienced grade 3 or 4 toxicities. No patient experienced grade 3 or 4 toxicities. While there was no rectal toxicity in patients with a hydrogel distance of $\geq 12.5 \mathrm{~mm}(\mathrm{n}=3)$, rectal toxicity was observed in one patient whose hydrogel distance was $10.5 \mathrm{~mm}$.

Table 1. Characteristics of patients and tumors

\begin{tabular}{|c|c|c|c|c|c|c|c|c|c|c|c|}
\hline \multirow[t]{2}{*}{$\begin{array}{l}\text { Patient } \\
\text { no }\end{array}$} & \multirow[t]{2}{*}{ Age } & \multirow[t]{2}{*}{ PSA } & \multirow[t]{2}{*}{$\mathbf{T}$} & \multirow[t]{2}{*}{ GS } & \multirow[t]{2}{*}{$\mathbf{N}$} & \multirow[t]{2}{*}{$\mathbf{M}$} & \multicolumn{3}{|c|}{$\begin{array}{l}\text { Distance between } \\
\text { prostate and rectum } \\
\text { distant }(\mathrm{mm})\end{array}$} & \multirow[t]{2}{*}{$\begin{array}{l}\text { Tenesmus } \\
\text { Frequency } \\
\text { (grade) }\end{array}$} & \multirow[t]{2}{*}{$\begin{array}{l}\text { Rectal } \\
\text { Toxicity } \\
\text { (grade) }\end{array}$} \\
\hline & & & & & & & $\mathrm{P} 1$ & $\mathrm{P} 2$ & P3 & & \\
\hline 1 & 62 & 16 & $\mathrm{~T} 2 \mathrm{c}$ & 6 & 0 & 0 & 19.1 & 25.2 & 18.4 & 3 & 0 \\
\hline 2 & 73 & 8 & $\mathrm{~T} 2 \mathrm{c}$ & 7 & 0 & 0 & 14.8 & 11.2 & 8.3 & 1 & 1 \\
\hline 3 & 63 & 10.5 & $\mathrm{~T} 2 \mathrm{c}$ & 6 & 0 & 0 & 12.5 & 11.1 & 9.4 & 1 & 1 \\
\hline 4 & 76 & 134 & T1c & 8 & 0 & 0 & 15.5 & 12.1 & 10.5 & 1 & 1 \\
\hline 5 & 64 & 9.6 & $\mathrm{~T} 2 \mathrm{c}$ & 6 & 0 & 0 & 15.7 & 12.5 & 9.5 & 1 & 0 \\
\hline 6 & 57 & 3.35 & $\mathrm{~T} 1 \mathrm{c}$ & 6 & 0 & 0 & 15.8 & 10.5 & 6.5 & 0 & 2 \\
\hline 7 & 61 & 4.04 & T1c & 6 & 0 & 0 & 25.1 & 17.2 & 11.5 & 0 & 0 \\
\hline
\end{tabular}

Abbreviations: GS: Gleson scor,T: tumor, N: Nodal metastasis, M: Distal Metastasis

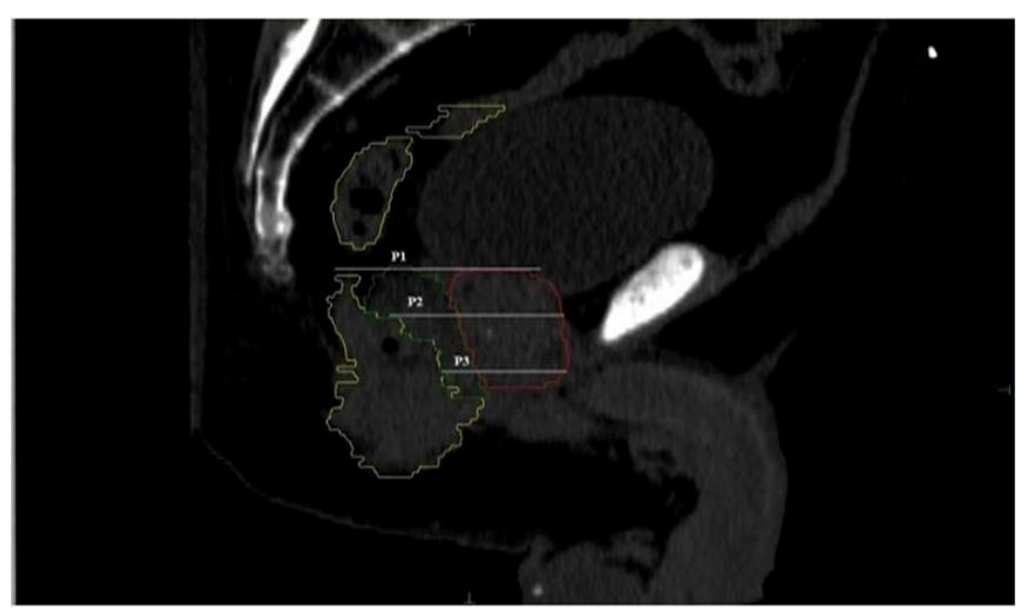

Figure 4. Sagittal CT reconstruction demonstrating the definition of the levels of the bases $\mathrm{P} 1, \mathrm{P} 2$ and $\mathrm{P} 3$. 
Table 2: Dosimetric comparison of both plans

\begin{tabular}{|l|lll|}
\hline \multicolumn{2}{|l}{ Non-Hydrogel Plan } & Hydrogel Plan & p value \\
\hline PTV78-D95 (Gy) & $75.9 \pm 0.3$ & $76.3 \pm 0.6$ & 0.09 \\
\hline PTV78-D5 (Gy) & $80.7 \pm 0.7$ & $81.1 \pm 0.6$ & 0.08 \\
\hline Rectum-V70 (\%) & $20 \pm 14.9$ & $11 \pm 2.2$ & 0.002 \\
\hline Rectum-V50 (\%) & $34 \pm 7.9$ & $28.2 \pm 11$ & 0.048 \\
\hline Rectum-V35 (\%) & $53.6 \pm 9.4$ & $51 \pm 14.6$ & 0.55 \\
\hline Bladder-V70 (\%) & $31.9 \pm 16.2$ & $21.5 \pm 9.9$ & 0.33 \\
\hline Bladder-V50 (\%) & $46.3 \pm 20.5$ & $37.6 \pm 16$ & 0.33 \\
\hline Bladder-V35 (\%) & $55.7 \pm 24$ & $48.7 \pm 21$ & 0.74 \\
\hline Penile bulb mean & $61.8 \pm 7.7$ & $61 \pm 6.6$ & 0.94 \\
\hline Penile bulb V40 & $85.6 \pm 11.6$ & $84 \pm 12.2$ & 0.98 \\
\hline Penile bulb V14 & $97.9 \pm 4$ & $98.3 \pm 2.8$ & 1.0 \\
\hline Right femur max (Gy) & $47.6 \pm 6.5$ & $50.6 \pm 3.7$ & 0.44 \\
\hline Left femur max (Gy) & $47.6 \pm 6.1$ & $49.1 \pm 2.7$ & 0.52 \\
\hline
\end{tabular}

\section{DISCUSSION}

Results of RT for treatment of PC are dose dependent. Medium risk patients treated with 78 Gy versus 70 Gy did better in a study conducted in the MD Anderson Centre, confirming the benefit of dose escalation however, it has been reported that dose escalation also results in increase in grade 2 rectal toxicity ( $25 \%$ vs $46 \%$, respectively) (Kuban et al., 2008). Reduction of rectal toxicity while maintaining high dose therapy has been possible by advanced technologies like IMRT and IGRT (Peeters et al., 2006; Zelefsky et al., 2006). While applying these methods for the treatment of local PC, reduction of rectal toxicity has gained prominence (Bohrer et al., 2008; Kuban et al., 2008; Viani et al., 2009; Zelefsky et al., 2006). Because of therapeutic complications, including rectal bleeding, proctitis, pain, and incontinence, which reduce life quality (Maeda, Høyer, Lundby, \& Norton, 2011; Pinkawa et al., 2010; Rancati et al., 2011). For this reason, various methods have been evaluated to reduce rectal toxicity. These include rectal balloon application (Patel, Orton, Tomé, Chappell, \& Ritter, 2003; Smeenk, Teh, Butler, van Lin, \& Kaanders, 2010; van Lin, Hoffmann, van Kollenburg, Leer, \& Visser, 2005; van Lin et al., 2007) and use of hyaluronic acid or collagen(Noyes, Hosford, \& Schultz, 2012; Prada et al., 2007; Wilder et al., 2010) with limited success. Recently, a new approach has been developed that involves injection of hydrogel between the prostate and rectum to allow rectal toxicity reduction (Pinkawa et al., 2011; Pinkawa et al., 2013; Pinkawa et al., 2015; Susil et al., 2010). Since the rectum is segregated from the target tissues by about $15 \mathrm{~mm}$, its exposure to damaging radiation is drastically reduced. In these patients, ratios of early and late toxicity are very low. In 
planning for PC RT, limiting dose prescriptions were designed to lower severe proctitis, necrosis or rectal fistula. The rectal doses of V50 and V70 should be $<50 \%$ and $20 \%$, respectively, and the maximum dose must be below 76 Gy. IMRT is better suited for these doses than the 3D-CRT. In our study, in which hydrogel was used in patients for 3D-CRT, we achieved this outcome by remaining way below these doses. Rectal V50 and V70 values were $28.2 \% \pm 11$ and $11 \% \pm 2.2$, which are statistically significant $(\mathrm{p}=0,048$ and $\mathrm{p}=0.002)$. When the distance between the prostate and rectum is considered in relation to toxicity, patients with a gap of over $15 \mathrm{~mm}$ show a decrease in toxicity near to statistically significant levels $(p=0.053)$. No toxicity was observed in patients in whom this distance was over $12.5 \mathrm{~mm}$. Lack of statistical significance is likely related to the low number of cases. For this reason, a distance of $12.5-15 \mathrm{~mm}$ seems sufficient.

Reporting of data pertaining to the use of hydrogel is increasing. In a recent study in which hydrogel was used during therapy, 3D-CRT and IMRT plans were compared dosimetrically (Pinkawa et al., 2011). It was found that the probability of dose related rectal toxicity decreased in both plans regardless of dose alterations of PTV and bladder. In a multicenter study, Uhl et al (Uhl et al., 2013) found that application of hydrogel during IMRT reduced rectal toxicity. In this study, in which 78 Gy RT was employed, no toxicity rating 3 or 4 was observed. The results of this study are similar to ours. Data for hydrogel use is also available for brachytherapy. Salvage brachytherapy was applied to a patient with recurrence following RT after hydrogel injection (Pinkawa et al., 2015). The risk of rectal fistula after surgical treatment is reported to be 3.4\% (Nguyen et al., 2013), but this approach limits rectal radiation exposure. In this way, it was shown that patients with recurrence post-RT can be treated by brachytherapy following hydrogel injection. Total RT dose cannot exceed 60-64 Gy because of rectal toxicity in patients with postoperative RT indication (Bolla et al., 2012; Thompson et al., 2009). However, by employing hydrogel, high dose RT (76 Gy) was successfully used to treat post-operative recurrence (Pinkawa et al., 2011). Hyrogel use is also well placed for the treatment of cervical cancer because of the anatomical location, requirement of high RT and radiation-induced rectal damage.

Hydrogel injection-induced hydrodisection facilitates linear and homogenous distribution (Nguyen et al., 2013). We utilized this method in our applications. In addition, intraoperative ultrasonography was used to monitor and ensure desired hydrogel placement. Non-homogenous distribution of hydrogel may result from the intensity of tenesmus after application. In one of our patients with $>10$ tenesmuses per day, the hydrogel space was $25 \mathrm{~mm}$ corresponding to the middle of the prostate. This results in pressure on the rectum that leads to tenesmuses. The complaints of the patient progressively decreased during therapy and disappeared before completion. This complication may adversely affect the wellbeing and adaptation to the therapy of the patient.

The gap created by hydrogel injection remains stable through RT and, depending on the resorption rate; it begins to shrink by about 6 months and disappears by 9 months (Uhl et al., 2013). In our cases, the hydrogel gap disappeared by 9 months which was verified by MRI (Figure 1).

\section{CONCLUSION}

3D-CRT can be successfully and safely applied at high intensity with low toxicity to prostate cancer patients after placing hydrogel between the rectum and prostate. We achieved important rectal protection by using hydrogel plans without expending on 
therapeutic dosages on PTV and bladder. This approach may bear importance for the treatment of cervical cancer patients, too. However, there is a requirement for studies analyzing the biochemical response and long term toxicity in larger patient groups, which may affect patient survival.

Conflicts of Interest: The authors declare no conflicts of interest.

Ethics Approval and Consent to Participate: Ethical consent was obtained from Recep Tayyip Erdogan Universitiy Local Ethics Committee. Decision no: 2017/45. Date: 17.03.2017.

Authors' Contributions: All authors participated in patient treatment and were involved in the preparation of the manuscript. All authors reviewed and approved the final manuscript.

Acknowledgments: We thank the physicists and technicians working at the Radiotherapy Department of the Teaching and Research Hospital of Rize.

\section{References}

Bohrer, M., Schröder, P., Welzel, G., Wertz, H., Lohr, F., Wenz, F., \& Mai, S. K. (2008). Reduced rectal toxicity with ultrasound-based image guided radiotherapy using $\mathrm{BAT}^{\mathrm{TM}}$ (B-mode acquisition and targeting system) for prostate cancer. Strahlentherapie und Onkologie, 184(12), 674.

Bolla, M., van Poppel, H., Tombal, B., Vekemans, K., Da Pozzo, L., De Reijke, T. M., ... Colombel, M. (2012). Postoperative radiotherapy after radical prostatectomy for high-risk prostate cancer: long-term results of a randomised controlled trial (EORTC trial 22911). The Lancet, 380(9858), 2018-2027.

Brenner, D. J. (2004). Fractionation and late rectal toxicity. International Journal of Radiation Oncology• Biology• Physics, 60(4), 1013-1015.

Bucci, M. K., Bevan, A., \& Roach, M., 3rd. (2005). Advances in radiation therapy: conventional to 3D, to IMRT, to 4D, and beyond. CA Cancer J Clin, 55(2), 117134.

Cox, J. D., Stetz, J., \& Pajak, T. F. (1995). Toxicity criteria of the radiation therapy oncology group (RTOG) and the European organization for research and treatment of cancer (EORTC). International Journal of Radiation Oncology• Biology• Physics, 31(5), 1341-1346.

Garzotto, M., \& Wajsman, Z. (1998). Androgen deprivation with salvage surgery for radiorecurrent prostate cancer: results at 5-year followup. J Urol, 159(3), 950954; discussion 954-955.

Jemal, A., Bray, F., Center, M. M., Ferlay, J., Ward, E., \& Forman, D. (2011). Global cancer statistics. CA Cancer J Clin, 61(2), 69-90. doi: 10.3322/caac.20107

Kuban, D. A., Tucker, S. L., Dong, L., Starkschall, G., Huang, E. H., Cheung, M. R., . . Pollack, A. (2008). Long-term results of the MD Anderson randomized dose- 
escalation trial for prostate cancer. International Journal of Radiation Oncology* Biology* Physics, 70(1), 67-74.

Maeda, Y., Høyer, M., Lundby, L., \& Norton, C. (2011). Faecal incontinence following radiotherapy for prostate cancer: a systematic review. Radiotherapy and Oncology, 98(2), 145-153.

Nederveen, A. J., van der Heide, U. A., Dehnad, H., van Moorselaar, R. J. A., Hofman, P., \& Lagendijk, J. J. (2002). Measurements and clinical consequences of prostate motion during a radiotherapy fraction. International Journal of Radiation Oncology* Biology* Physics, 53(1), 206-214.

Nguyen, P. L., Devlin, P. M., Beard, C. J., Orio III, P. F., O'Leary, M. P., Wolfsberger, L. D., . . Hohenfellner, M. (2013). High-dose-rate brachytherapy for prostate cancer in a previously radiated patient with polyethylene glycol hydrogel spacing to reduce rectal dose: case report and review of the literature. Brachytherapy, 12(1), 77-83.

Noyes, W. R., Hosford, C. C., \& Schultz, S. E. (2012). Human collagen injections to reduce rectal dose during radiotherapy. International Journal of Radiation Oncology* Biology* Physics, 82(5), 1918-1922.

Patel, R. R., Orton, N., Tomé, W. A., Chappell, R., \& Ritter, M. A. (2003). Rectal dose sparing with a balloon catheter and ultrasound localization in conformal radiation therapy for prostate cancer. Radiotherapy and Oncology, 67(3), 285294.

Peeters, S., Heemsbergen, W. D., Koper, P., Van Putten, W., Slot, A., Dielwart, M., . . . Lebesque, J. V. (2006). Dose-response in radiotherapy for localized prostate cancer: results of the Dutch multicenter randomized phase III trial comparing 68 Gy of radiotherapy with 78 Gy. J Clin Oncol, 24(13), 1990-1996.

Pinkawa, M., Asadpour, B., Gagel, B., Piroth, M. D., Holy, R., \& Eble, M. J. (2006). Prostate position variability and dose-volume histograms in radiotherapy for prostate cancer with full and empty bladder. International Journal of Radiation Oncology* Biology* Physics, 64(3), 856-861.

Pinkawa, M., Corral, N. E., Caffaro, M., Piroth, M. D., Holy, R., Djukic, V., . . Eble, M. J. (2011). Application of a spacer gel to optimize three-dimensional conformal and intensity modulated radiotherapy for prostate cancer. Radiotherapy and Oncology, 100(3), 436-441.

Pinkawa, M., Holy, R., Piroth, M. D., Fischedick, K., Schaar, S., Székely-Orbán, D., \& Eble, M. J. (2010). Consequential late effects after radiotherapy for prostate cancer-a prospective longitudinal quality of life study. Radiation Oncology, $5(1), 27$.

Pinkawa, M., Piroth, M. D., Holy, R., Escobar-Corral, N., Caffaro, M., Djukic, V., ... Eble, M. J. (2013). Spacer stability and prostate position variability during 
radiotherapy for prostate cancer applying a hydrogel to protect the rectal wall. Radiotherapy and Oncology, 106(2), 220-224.

Pinkawa, M., Schubert, C., Escobar-Corral, N., Holy, R., \& Eble, M. J. (2015). Application of a hydrogel spacer for postoperative salvage radiotherapy of prostate cancer. Strahlentherapie und Onkologie, 191(4), 375-379.

Prada, P. J., Fernández, J., Martinez, A. A., De La Rua, A., Gonzalez, J. M., Fernandez, J. M., \& Juan, G. (2007). Transperineal injection of hyaluronic acid in anterior perirectal fat to decrease rectal toxicity from radiation delivered with intensity modulated brachytherapy or EBRT for prostate cancer patients. International Journal of Radiation Oncology* Biology* Physics, 69(1), 95-102.

Prada, P. J., Gonzalez, H., Menendez, C., Llaneza, A., Fernández, J., Santamarta, E., \& Ricarte, P. P. (2009). Transperineal injection of hyaluronic acid in the anterior perirectal fat to decrease rectal toxicity from radiation delivered with low-doserate brachytherapy for prostate cancer patients. Brachytherapy, 8(2), 210-217.

Rancati, T., Fiorino, C., Fellin, G., Vavassori, V., Cagna, E., Borca, V. C., .. . Tortoreto, F. (2011). Inclusion of clinical risk factors into NTCP modelling of late rectal toxicity after high dose radiotherapy for prostate cancer. Radiotherapy and Oncology, 100(1), 124-130.

Robinson, J. W., Moritz, S., \& Fung, T. (2002). Meta-analysis of rates of erectile function after treatment of localized prostate carcinoma. Int J Radiat Oncol Biol Phys, 54(4), 1063-1068.

Smeenk, R. J., Teh, B. S., Butler, E. B., van Lin, E. N., \& Kaanders, J. H. (2010). Is there a role for endorectal balloons in prostate radiotherapy? A systematic review. Radiother Oncol, 95(3), 277-282. doi: 10.1016/j.radonc.2010.04.016

Stephenson, A. J., Scardino, P. T., Bianco, F. J., Jr., DiBlasio, C. J., Fearn, P. A., \& Eastham, J. A. (2004). Morbidity and functional outcomes of salvage radical prostatectomy for locally recurrent prostate cancer after radiation therapy. $J$ Urol, 172(6 Pt 1), 2239-2243.

Susil, R. C., McNutt, T. R., DeWeese, T. L., \& Song, D. (2010). Effects of prostaterectum separation on rectal dose from external beam radiotherapy. International Journal of Radiation Oncology* Biology* Physics, 76(4), 1251-1258.

Teh, B. S., Bastasch, M. D., Wheeler, T. M., Mai, W.-Y., Frolov, A., Uhl, B. M., . . McGary, J. (2003). IMRT for prostate cancer: defining target volume based on correlated pathologic volume of disease. International Journal of Radiation Oncology* Biology* Physics, 56(1), 184-191.

Thompson, I. M., Tangen, C. M., Paradelo, J., Lucia, M. S., Miller, G., Troyer, D., . . . Swanson, G. (2009). Adjuvant radiotherapy for pathological T3N0M0 prostate cancer significantly reduces risk of metastases and improves survival: long-term followup of a randomized clinical trial. J Urol, 181(3), 956-962. 
Uhl, M., Van Triest, B., Eble, M. J., Weber, D. C., Herfarth, K., \& De Weese, T. L. (2013). Low rectal toxicity after dose escalated IMRT treatment of prostate cancer using an absorbable hydrogel for increasing and maintaining space between the rectum and prostate: results of a multi-institutional phase II trial. Radiotherapy and Oncology, 106(2), 215-219.

van Lin, E. N., Hoffmann, A. L., van Kollenburg, P., Leer, J. W., \& Visser, A. G. (2005). Rectal wall sparing effect of three different endorectal balloons in 3D conformal and IMRT prostate radiotherapy. Int J Radiat Oncol Biol Phys, 63(2), 565-576. doi: 10.1016/j.ijrobp.2005.05.010

van Lin, E. N., Kristinsson, J., Philippens, M. E., de Jong, D. J., van der Vight, L. P., Kaanders, J. H., . . . Visser, A. G. (2007). Reduced late rectal mucosal changes after prostate three-dimensional conformal radiotherapy with endorectal balloon as observed in repeated endoscopy. Int J Radiat Oncol Biol Phys, 67(3), 799811. doi: 10.1016/j.ijrobp.2006.09.034

Viani, G. A., Stefano, E. J., \& Afonso, S. L. (2009). Higher-than-conventional radiation doses in localized prostate cancer treatment: a meta-analysis of randomized, controlled trials. International Journal of Radiation Oncology* Biology* Physics, 74(5), 1405-1418.

Wilder, R. B., Barme, G. A., Gilbert, R. F., Holevas, R. E., Kobashi, L. I., Reed, R. R., ... Mesa, A. V. (2010). Cross-linked hyaluronan gel reduces the acute rectal toxicity of radiotherapy for prostate cancer. International Journal of Radiation Oncology* Biology* Physics, 77(3), 824-830.

Zelefsky, M. J., Chan, H., Hunt, M., Yamada, Y., Shippy, A. M., \& Amols, H. (2006). Long-term outcome of high dose intensity modulated radiation therapy for patients with clinically localized prostate cancer. J Urol, 176(4), 1415-1419. 